\title{
Physico-chemical modifications of conjugated linoleic acid for ruminal protection and oxidative stability Hyun-Seuk Moon ${ }^{1}$, Hong-Gu Lee ${ }^{2}$, Chung-Soo Chung ${ }^{3}$, Yun-Jaie Choi ${ }^{4}$ and Chong-Su Cho*4
}

Address: ${ }^{1}$ Laboratory of Molecular Signaling, National Institute on Alcohol Abuse and Alcoholism, National Institutes of Health, Bethesda, Maryland 20892-9410, USA, 2School of Bio-Resources and PNU-Special Animal Biotechnology Center, Pusan National University, Miryang, 627706, South Korea, ${ }^{3}$ College of Agriculture, Life \& Environment Sciences, Chungbuk National University, Cheongju 361-763, South Korea and ${ }^{4}$ School of Agricultural Biotechnology, Seoul National University, Seoul 151-921, South Korea

Email: Hyun-Seuk Moon - moonh2@mail.nih.gov; Hong-Gu Lee - hglee66@snu.ac.kr; Chung-Soo Chung - chungpig@hotmail.com; YunJaie Choi - cyjcow@snu.ac.kr; Chong-Su Cho* - chocs@plaza.snu.ac.kr

* Corresponding author

Published: I June 2008

Nutrition \& Metabolism 2008, 5:16 doi:10.1186/1743-7075-5-16
Received: 26 January 2008

Accepted: I June 2008

This article is available from: http://www.nutritionandmetabolism.com/content/5/1/16

(c) 2008 Moon et al; licensee BioMed Central Ltd.

This is an Open Access article distributed under the terms of the Creative Commons Attribution License (http://creativecommons.org/licenses/by/2.0), which permits unrestricted use, distribution, and reproduction in any medium, provided the original work is properly cited.

\begin{abstract}
Conjugated linoleic acid (CLA) is a mixture of positional and geometric isomers of octadecadienoic acid [linoleic acid (LA), 18:2n-6]. Although ruminant milk and meat products represent the largest natural source of CLA and therefore, their concentration in ruminant lipids are of interest to human health, chemical or physical modifications of CLA should be needed as a means to enhance oxidative stability, to improve post-ruminal bioavailability, and to increase the clinical application. In fact, CLA are rapidly decomposed to form furan fatty acids when its are oxidized in air, and the effectiveness of dietary supplements of CLA may be related to the extent that their metabolisms by rumen bacteria are avoided. For these reasons, many scientists have examined the effect of manufacturing and protection on the stability of CLA in ruminants and food products. In this review, physico-chemical modifications of CLA for ruminal protection such as calcium salt $(\mathrm{Ca})$, formaldehyde protection (FP), lipid encapsulation (LE), and amide linkage (AL), and for oxidative stability such as green tea catechin (GTC), cyclodextrin (CD), arginine (Arg), amylase, and PEGylation are proposed.
\end{abstract}

\section{Background}

Conjugated linoleic acid (CLA) are a collective term for a group of positional (C8,C10; $\mathrm{C} 9, \mathrm{C} 11 ; \mathrm{C} 10, \mathrm{C} 12$; and $\mathrm{C} 11, \mathrm{C} 13$ ) and geometric (cis,cis; cis,trans; trans,cis; and trans,trans) isomers of octadecadienoic acid (linoleic acid, LA) with a conjugated double-bond system [1]. Also, the major and most important formation of CLA are the endogenous desaturation of vaccenic acid (VA) due to the action of stearoyl-CoA desaturase (SCD; also so-called delta-9 desaturase) $[1,2]$. The CLA are effective in protecting tissues from carcinogenesis [2], reducing the develop- ment of atherosclerosis [3], stimulating the immune system [4], and inducing enzyme change in mouse liver $[5,6]$. These effects appear to be mediated by two isomers of CLA, and the two biologically active isomers are the cis9, trans11 and trans10, cis12 [7,8]. Also, it is well known that the CLA content in ruminant-derived food are certainly more affected by the animal diet and production system than by food-manufacturing factors [9]. Several factors influence the CLA content of food products, such as temperature, protein, quality, choice of starter cultures, and period of aging [10]. Variations of CLA content in 
foods are also affected by the animal's diet, animal age and breed, and seasonal factors [10-12]. Unfortunately, physical or chemical modification of CLA should be needed when its are to be used in food systems as fortifiers or additives. In fact, a number of methods have been used to prepare "rumen-protected" feed supplements, and their efficacy can be described by the extent of protection from rumen bacteria as well as post-ruminal bioavailability [13]. Also, CLA are extremely unstable in air and cis, cisCLA isomers are most susceptible to oxidative degradation while the four trans, trans-CLA isomers are most stable in air [14], indicating that the CLA must be protected from oxidation. This review is attempted to propose various physico-chemical modification methods of CLA for ruminal protection and oxidative stability, and the potential of clinical applications of CLA is also explained.

\section{Origin and structure of CLA}

\section{I. Origin of CLA}

Polyunsaturated fatty acids (PUFA) other than CLA, with a conjugated double bond system and with more than two double bonds, occurred naturally in nature in various seed oils but their biological activity had to date not been extensively investigated when compared with data available for CLA [15-18]. The first step in the biohydrogenation of dietary LA resulted in the formation of the cis9, trans 11 isomer, due to isomerization and transposition of the delta-12 double bond [16]. This was the most abundant natural isomer present in ruminant tissue fats (over 90\% of total CLA) and had been termed rumenic acid (RA) $[16,19]$. Further hydrogenation of RA resulted in the production of trans11-18:1 VA which was the major transmonounsaturated fatty acid present in the fats of ruminant food products (milk, yoghurt, cheese, butter, and meats) $[19,20]$. This contrasts with commercial preparations of CLA where proportions of the two main isomers were usually equal, although the chemical method for synthesis will allow a variety of ratios for the two isomers in the final mixture [16]. Meat from ruminant animals, particularly the fat associated with meat, was also an important source of CLA, contributing in the region of 25 to $30 \%$ of the total food intake in Western populations $[16,19]$. Isomers of CLA could also be synthesized in the laboratory from C18:2 or from sources high in C18:2, such as sunflower, safflower, soybean, or corn oils by a reaction involving alkaline water isomerization [19-22] and isomerization in propylene glycol $[20,21,23]$. The predominant isomer in milk and other dairy products was the cis9, trans 11 with minor but significant proportions of trans10, cis12 $[16,19,20]$.

\section{2. Structure of CLA}

CLA were a series of positional and geometric isomers of LA where one or both of the double bonds are either in the cis or the trans configuration and transposed to differ- ent positions along the acyl chain with the bonds separated by a simple carbon-carbon linkage rather than by the normal methylene group $[16,17]$. A number of cis-cis, cis-trans, trans-cis, and trans-trans isomers with the double bonds at various locations along the acyl chain, from carbon- 6 to carbon-15, had been identified by various chemical reductive, chromatographic, and spectroscopic techniques $[16,18,19]$. A total of natural CLA isomers had been found in milk, dairy products, beef, human milk, and human adipose tissue using silver ion-high performance liquid chromatography and gas chromatographyelectron ionization mass spectrometry [23-26].

\section{Physiological and biological effects of CLA on health and disease}

There have been few studies that have examined the effects of CLA or its isomers in humans. Recently, a wealth of literature available mainly from cell line and animal studies indicates that CLA and individual isomers (especially, C9,T11 and T10,C12) may have numerous health benefits. One of the first studies in healthy adult women examined the effects of $3 \mathrm{~g}$ /day intake of CLA for 64 days on fat-free mass, fat mass and percentage fat mass compared to sunflower oil (SFO) placebo, and the results showed that there were no differences in body composition or any of the parameters examined [27]. However, two studies from Norway in healthy exercising humans (CLA, $1.8 \mathrm{~g} /$ day) and in overweight and obese humans (CLA, 1.7, 3.4, 5.1, and $6.8 \mathrm{~g} /$ day) for 12 weeks showed that CLA can decrease fat mass without significantly affecting body weight $[28,29]$. Results of the first study in athletes were encouraging considering that a much lower dose of CLA ( $1.8 \mathrm{~g} /$ day) produced significant results compared to the second study where the authors concluded that a dose of $3.4 \mathrm{~g} /$ day of CLA was enough to cause reduction of body fat. Another study in 2001 evaluated the effects of intake of $4.2 \mathrm{~g}$ CLA/day for 4 weeks on changes in adipose tissue and cardiovascular risk factors in middle-aged obese men with signs of metabolic syndrome [30]. In an interesting study from Netherlands, 13-week intervention with 1.8 or $3.6 \mathrm{~g} /$ day CLA in overweight humans supplemented prior to this with a very-low-calorie diet (which induced weight loss) increased resting metabolic rate and lean mass without affecting body weight regain [31]. Other studies had previously showed a net decrease in body fat greater than net decrease in body weight, suggesting that lean mass may have increased in the subjects $[28,29]$. Volunteers in both these studies were either on intensive training programs or exercised for 90 min, three times per week. These studies seem to suggest that exercise could enhance the fat-lowering effects of CLA and also help improve lean mass in humans. However, there is very limited literature on human studies with individual and different ratios of isomers, which makes it difficult to clearly establish the protective role of the 
physiological and biologically effect of CLA isomers in improving human health. In fact, recent studies in animals and humans suggest that CLA may not have adverse effects with long-term intervention and may actually be beneficial in reducing fat mass and atherogenic lipids [32]. Also, very few clinical studies have focused on the effects of CLA on bone health and cancer, and there are also differences in the way CLA was supplemented. In addition, effect of CLA and its isomers on inflammatory mediators has not been the subject of extensive research in humans and need to be pursued urgently. Overall, more well-controlled studies are needed before CLA or enriched isomers can be recommended to humans with confidence to improve health and quality of life. Also, evidence for efficacy in humans is being steadily strengthened by the results from clinical trials as well as animal toxicology tests.

\section{Ruminal protection of CLA}

Since ruminant milk and meat products represented the largest natural source of CLA and therefore, their concentration in ruminant lipids was of interest to human health although only trans 10 , cis 12 was primarily mentioned which was used in the studies to obtain milk fat depression [33]. A technology to reduce milk fat output in a controlled manner had a potential application as a management tool [34]. However, the effectiveness of dietary supplements of CLA may be related to the extent that their metabolism by rumen bacteria was avoided [13,34]. Hence, a number of processes had been used to manufacture "rumen-protected" feed supplements, and their efficacies were described by the extent of protection from rumen bacteria as well as post-ruminal bioavailability $[13,35]$. Several methods had been used to reduce the extent to which lipid supplements were metabolized by rumen bacteria. These included the formation of calcium salts [15,36-38], amide linkages [13,36,37], [39-41], formaldehyde treatment [15], and lipid encapsulation $[13,30,42,43]$. The form of fatty acid required for the production of these supplements varies, and became an important consideration due to the variation in manufacturing processes and costs associated with the production of different lipid forms.

\section{I. Calcium salt}

Calcium salts ( $\mathrm{Ca}$ ) of fatty acids had been commercially used as a dietary lipid supplement for dairy cows, and they had been experimentally used to provide rumen-protected supplements of CLA $[15,36]$. Giesy et al. reported that milk fat percentage was reduced in a dose-dependent manner by feeding Ca-CLA [36]. The predicted equation followed data well and showed the expected decrease in milk fat percentage as dose increased, indicating that $\mathrm{Ca}$ CLA provided with the opportunity to regulate milk fat synthesis with only a minor dietary addition (Fig. 1A).
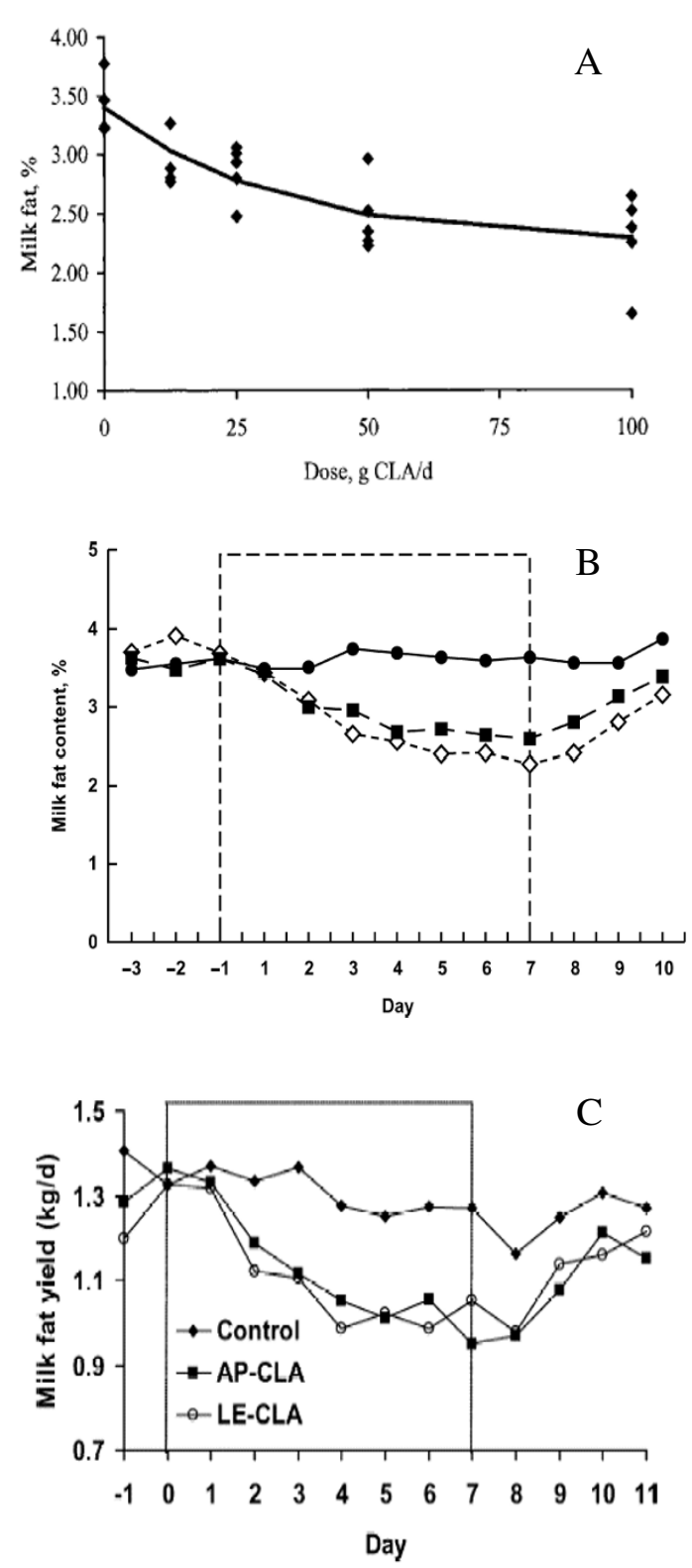

Figure I

(A) Relationship between dose of conjugated linoleic acid (CLA) as calcium salts and milk fat percentage in Holstein cows on the fifth days of CLA feeding. Graph illustrates predicted exponential regression model $\left(y=1.114 * \mathrm{e}^{-0.033 x+}\right.$ 2.249) (J Dairy Sci 2002, 85:2023-2029). (B) Temporal pattern of milk fat content in cow $(n=3)$ during intraruminal infusion of different rumen-protected conjugated linoleic acid (CLA) formulations. Treatments were control (no added lipid; •), calcium salt of CLA (•), and formaldehyde-protected CLA $(\diamond)$ (J Dairy Sci 2005, 88: I685-1693). (C) Temporal pattern of milk fat yield during supplementation of rumen-protected CLA supplements [amide-protected CLA (AP-CLA): lipid-encapsulated-CLA (LE-CLA)] (J Dairy Sci 2004, 87:30 I03016) 
These effects were caused by the trans10, cis12 CLA. The extent of the effect was certainly higher by using the form of a Ca because it protected the fatty acid from microbial degradation. Moreover, supplementing dairy cows with rumen-protected forms of CLA such as Ca-CLA substantially reduced the yield and content of milk fat without altering other production responses [15]. Similar effects on milk fatty acid pattern had been reported in previous studies where cows had received Ca-CLA [37], and studies involving abomasal infusion of trans10, cis12 CLA, where effects on de novo synthesized fatty acids became more pronounced as the dose of trans 10 , cis12 CLA increased [38].

\section{2. Formaldehyde protection}

Formaldehyde protection (FP) enabled the use of either FFA or esterified fatty acids [15]. Figure 1B and Table 1 showed that the CLA supplements resulted in a progressive reduction in milk fat content through the first few days of the treatment period and the proportion of preformed fatty acids in milk fat was increased with CLA treatment, whereas short- and medium-chain fatty acids tended to decrease, indicating that both protection forms such as Ca and FP were effective methods for the formulation of CLA supplements to induce milk fat depression (MFD) in lactating dairy cows and the transfer of trans10, cis12 CLA into milk fat for both Ca-CLA and FP-CLA supplements was much lower than that previously reported when CLA were supplied post-ruminally. As expected, the CLA treatments resulted in increased concentrations of trans10, cis12 CLA in milk fat, with the increase for FPCLA treatment being greater than the Ca-CLA treatment.

\section{3. Lipid encapsulation}

Recent work showed that the FFA and methyl ester forms of trans10, cis12 CLA were equally effective in reducing milk fat synthesis when supplied by abomasal infusion [39]. Also, Perfield et al. observed a gradual reduction in milk fat yield over the first few days of treatment and a return to control values when the supplement was terminated [13], and this was similar to changes observed when trans10, cis12 CLA were abomasally infused [42] or provided intravenously [43]. It was found that the lipid encapsulation (LE) of CLA supplement was manufactured by binding methyl esters of CLA to a silica matrix, and then coating this complex with hydrogenated soybean oil, which contained fatty acids in the triglyceride form.

\section{4. Amide linkage}

Although Ca and FP of fatty acids had been commercially used as a dietary lipid supplement for dairy cows, and they had also been experimentally used to provide rumen-protected supplements of CLA [36,37], only few studies had been performed to suggest the rumen-protected supplements of CLA on amide protection (AP) methods. A simple AP supplement required that the starting material be FFA, whereas other amide-protected supplements had been manufactured from oils, and esters or other forms could be used for FP or LE [40]. Perfield et al. examined the use of AP and LE as methods to supply CLA [13]. It was found that the AP supplement provided CLA as FFAs, whereas the LE supplement provided CLA as methyl esters, suggesting that the AP-CLAs supplements resulted in decreased secretion of milk fatty acids of all chain lengths, but the reduction was relatively greater for milk fatty acids containing $\leq 16$ carbons (Fig. 1C and Table 2). These results indicated that the AP-CLA supplements were able to reduce milk fat in a controlled manner with no adverse effects. Recent work had also reported that the FFA and methyl ester (ME) forms of trans10, cis12 CLA were equally effective in reducing milk fat synthesis when supplied by abomasal infusion [39] and CLA-ME could be

Table I: Intake and milk production results during intraruminal administration of rumen-protected conjugated linoleic acid (CLA) $U$ Dairy Sci 2005, 88: 1685-1693).

\begin{tabular}{|c|c|c|c|c|c|c|}
\hline & \multicolumn{3}{|c|}{ Treatment ${ }^{1}$} & \multirow[b]{2}{*}{ SEM } & \multicolumn{2}{|c|}{$P$} \\
\hline & Control & Ca-CLA & FP-CLA & & CLA $^{2}$ & Type $^{3}$ \\
\hline DMI, kg/d & 23.6 & 23.1 & 23.3 & 1.13 & 0.68 & 0.84 \\
\hline Milk yield, kg/d & 21.9 & 20.6 & 19.5 & 2.32 & 0.31 & 0.57 \\
\hline \multicolumn{7}{|l|}{ Milk fat } \\
\hline$\%$ & 3.61 & 2.61 & 2.34 & 0.27 & $<0.01$ & 0.18 \\
\hline $\mathrm{g} / \mathrm{d}$ & 788 & 517 & $44 I$ & 42 & 0.02 & 0.30 \\
\hline \multicolumn{7}{|l|}{ Milk protein } \\
\hline$\%$ & 3.16 & 3.38 & 3.48 & 0.17 & 0.08 & 0.40 \\
\hline $\mathrm{g} / \mathrm{d}$ & 690 & 673 & 669 & 50 & 0.64 & 0.93 \\
\hline SCC, $\times 1000$ & 150 & 114 & 137 & 98 & 0.44 & 0.52 \\
\hline
\end{tabular}

IValues represent mean from d 6 and 7 for control (no added lipid) and intraruminal administration calcium salts of CLA (Ca-CLA) and formaldehyde-protected CLA (FP-CLA).

${ }^{2}$ Contrast between control and the combined CLA treatments.

${ }^{3}$ Contrast between Ca-CLA and FP-CLA treatments. 
Table 2: Performance of lactating dairy cows receiving rumenprotected supplements of conjugated linoleic acid (CLA) ${ }^{1,2} \mathrm{U}$ Dairy Sci 2004, 87:30 I 0-30 I6).

\begin{tabular}{|c|c|c|c|c|c|}
\hline \multirow[b]{2}{*}{ Variable } & \multicolumn{3}{|c|}{ Treatment } & \multirow[b]{2}{*}{ SEM } & \multirow[b]{2}{*}{$\boldsymbol{P}^{3}$} \\
\hline & Control & AP-CLA & LE-CLA & & \\
\hline DMI, kg/d & 30.6 & 31.6 & 30.4 & 0.9 & 0.50 \\
\hline Milk, kg/d & 40.5 & 42.6 & 42.7 & 3.5 & 0.32 \\
\hline \multicolumn{6}{|l|}{ Milk fat } \\
\hline$\%$ & $3.23^{a}$ & $2.37 \mathrm{~b}$ & $2.34^{b}$ & 0.15 & $<0.001$ \\
\hline $\mathrm{kg} / \mathrm{d}$ & 1.272 & $1.004 b$ & $0.992^{\mathrm{b}}$ & 0.079 & $<0.001$ \\
\hline \multicolumn{6}{|c|}{ Milk protein } \\
\hline$\%$ & 2.55 & 2.51 & 2.58 & 0.12 & 0.07 \\
\hline $\mathrm{kg} / \mathrm{d}$ & $1.001 \mathrm{~b}$ & $1.063^{\mathrm{a}}$ & 1.086 & 0.023 & 0.02 \\
\hline
\end{tabular}

a,bMeans within a row with different superscripts differ.

ISupplements were amide-protected CLA (AP-CLA) and lipidencapsulated CLA (LE-CLA).

${ }^{2} V$ alues represent an average of day 6 and 7 of supplementation.

${ }^{3}$ Statistical probability of treatment effects.

protected from ruminal metabolism and inclusion of RPME-CLA supplement in the diet reduced milk fat content by $35-40 \%$ and significantly increased the concentration of CLA isomers in milk [41]. Overall, supplementation of an AP-CLA or a LE-CLA product resulted in similar reductions in milk fat with no effect on feed intake or milk yield. Although reduction in milk fat yield had achieved nadir by the sixth day of supplementation, transfer of trans10, cis12 CLA into milk fat was similar for both rumen-protected CLA products, and the AP-CLA and LECLA supplements were able to reduce milk fat in a controlled manner with no adverse effects [13], as this was a short-term study with very limited animal numbers, further research with these supplements would be needed to verify and extend results.

\section{Oxidative stability of CLA}

Some of the studies had shown that CLA acted as an antioxidant although some other studies had been reported that CLA might be pro-oxidant. Anti-oxidant activity of CLA was observed in mammary gland tissues from rats fed with CLA, when evaluated by the thiobarbituric acid reactive substances (TBARS) values [44]. However, CLA did not reduce TBARS values in pork patties mixed with CLA $[44,45]$ and in in vitro study; CLA were oxidized as rapidly as LA $[12,46]$. In fact, CLA were extremely unstable in air and cis, cis-CLA isomers were most susceptible to oxidative degradation while the four trans, trans-CLA isomers were most stable in air under same conditions [14]. Moreover, CLA were oxidized faster than LA, suggesting that a conjugated double bond was more vulnerable to auto-oxidation than a non-conjugated double bond. This was in agreement with those of previous observations $[14,47,48]$, indicating that CLA must be protected from oxidation when it was to be used in food systems as fortifiers or additives.

\section{I. Green tea catechins}

Dietary supplements containing green tea extracts were expected to be comprised of polyphenolic compounds called catechins, which were commonly obtained from green tea. The catechins were believed to act as anti-oxidants and free radical scavengers having chemo-preventative behavior as well as protection against coronary heart disease and attenuation of high blood pressure [40]. The catechins common to all green teas were (-)-epigallocatechin (EGC), (+)-catechin (C), (-)-epigallocatechin-3-gallate (EGCG), (-)-epicatechin (EC), and (-)-epicatechin gallate (ECG) [49]. Also, it was known that green tea catechins were strong anti-oxidants [50]. Seo et al. reported that CLA was more stable than LA in the aqueous system when 2,2'-azobis(2-amidinopropan) dihydrochloride was used as a free radical initiator [51]. Also, jasmine green tea catechins (GTC) (200 ppm) were effective as an anti-oxidant in protecting CLA from oxidation and the inhibition of 200 ppm GTC on CLA oxidation was even stronger than that of $200 \mathrm{ppm}$ butylated hydroxytoluene (BHT) under the same conditions [40]. The oxygen consumption test showed that the oxygen uptake by the CLA samples was considerably more unstable than LA, whereas addition of $200 \mathrm{ppm}$ GTC significantly decreased the oxygen uptake by CLA as compared with the control CLA samples (Fig. 2A). It is noteworthy that $200 \mathrm{ppm}$ GTC is more effective than $200 \mathrm{ppm}$ BHT in protecting CLA from oxidation. It is known that canola oil contains $\alpha$-tocopherol and it is also possible that GTC and $\alpha$-tocopherol have a synergistic effect on the oxidation of CLA when added in canola oil [52]. Also, feeding canola seed to lactating dairy cows resulted in milk fat with higher proportions of healthful fatty acids without affecting milk yield or composition of milk [53].

\section{2. Cyclodextrin/CLA complex}

$\alpha-, \beta$-, and $\gamma$-cyclodextrins, consisting of 6,7 , and $8 \mathrm{D}(+)$ glucopyranose units connected by $\alpha(1 \rightarrow 4)$ glucosidic bond, respectively, are well known cyclodextrins (CDs) for food industry [54]. The CDs were known to form inclusion complexes with various compounds, ranging from polar to highly non-polar agents [55]. Also, PUFA encapsulated in $\alpha$ - and $\beta$-CDs had been shown to protect completely against oxidation even in pure oxygen [56]. Oxidative stability of CLA encapsulated in $\alpha-, \beta-$, and $\gamma$ cyclodextrins (designated as CLA/CDs microencapsules) was studied by measuring the headspace-oxygen depletion in airtight serum bottles and by measuring the peroxide values (POV) [57]. It was found that CLA/ $\alpha-C D$ microencapsules at a 1:4 mole ratio completely protected CLA from oxidation, when oxidized at $35^{\circ} \mathrm{C}$ and a $1: 6$ mole ratio of CLA $/ \beta-\mathrm{CD}$ was required to give a protective 

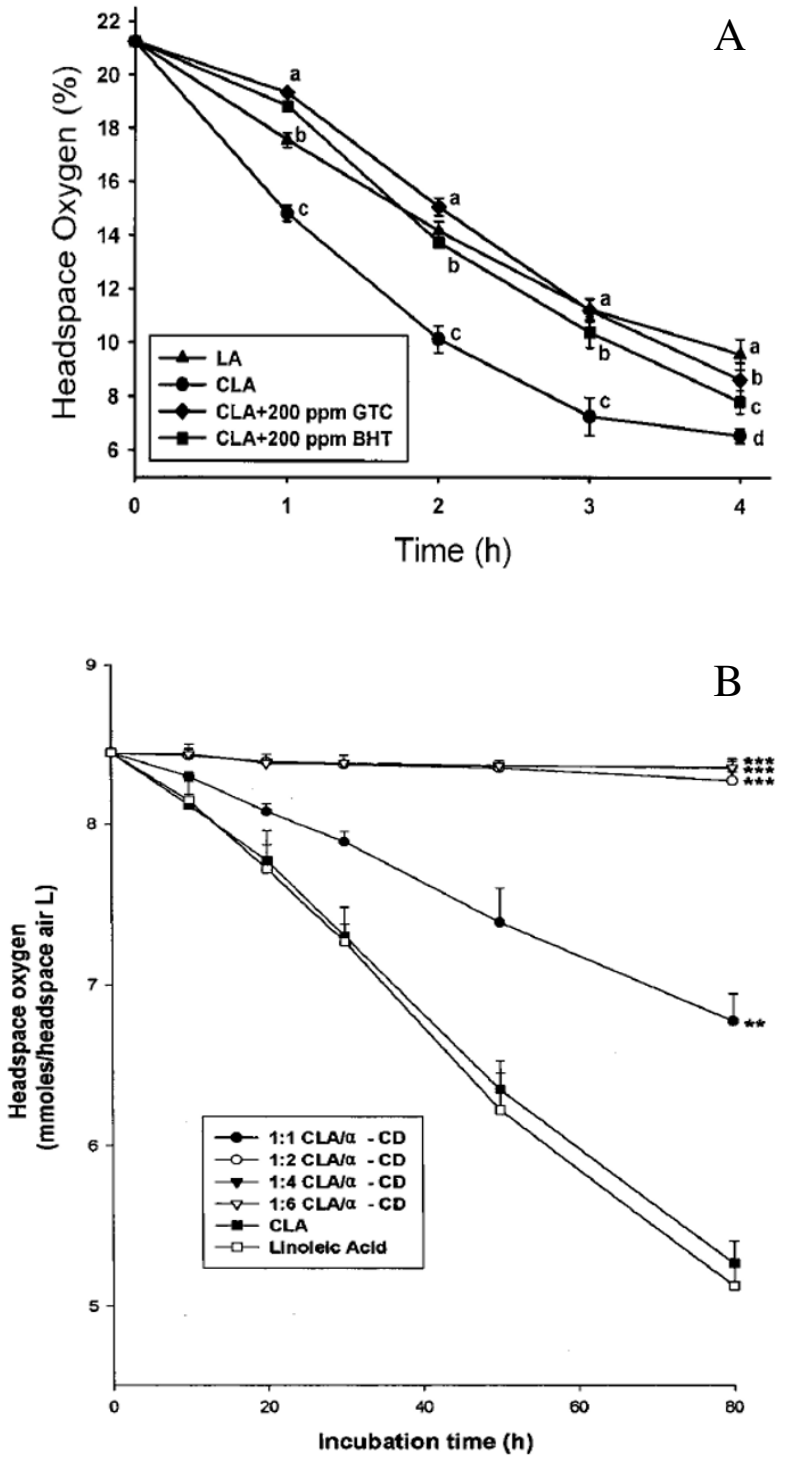

\section{Figure 2}

(A) Headspace-oxygen consumption profile of LA and CLA with or without addition of 200 ppm GTC or 200 ppm BHT at $90^{\circ} \mathrm{C}$. Data are expressed means \pm SD for $n=5$ samples. Means at the same time point with different superscript letters (a-d) differ significantly $(p<0.05)$ (J Agric Food Chem 2000, 48:3072-3076). (B) Headspace-oxygen depletion by $C L A / \alpha-C D$ microencapsulations. The CLA/ $\alpha-C D$ microencapsules were incubated in a shaking incubator $\left(35^{\circ} \mathrm{C}, 250\right.$ rpm) for a period $80 \mathrm{~h}$. Two and three asterisks represent that headspace-oxygen depletion is significantly different from that of the control, incubated for $80 \mathrm{~h}$, at $\mathrm{p}<0.0 \mathrm{I}$ and $\mathrm{p}$ $<0.00$ I levels, respectively, by Tukey's w significant test $(J$ Agri Food Chem 2000, 48:3922-3929).

effect similar to that exhibited by CLA $/ \gamma$-CD microencapsules at a 1:4 mole ratio (Fig. 2B). The protective efficiency of CDs for CLA oxidation may be, in part, attributed to the hydrophobicity of the inner cavity of CDs, which facilitated insertion of the conjugated diene portion into the $\mathrm{CD}$ cavity, and the cavity of the CDs, which was possibly large enough to incorporate some oxygen molecules and create a miniature reaction chamber to facilitate the reaction between CLA and oxygen, suggesting that physical interference by CDs was not a negligible factor for the oxidative stability of CLA. Further study will be required to explore the structural features of CLA/CDs microencapsules. It was of significance to note that $\beta$-CD was an appropriate material with which to microencapsulate CLA for industrial use, because of its adequate protective effects for CLA oxidation and because it was much lower in cost than other CDs.

\section{3. Arginine/CLA complex}

Arginine (Arg), a water-soluble amino acid, was known to be a substrate of nitric oxide synthase and regulate vascular function and blood pressure homeostasis, and thus prevent cardiovascular disease [58]. Also, Arg had some protective roles against oxygen radical attack possibly due to its direct chemical interaction with oxygen radicals [59]. Kim et al. reported that hydroperoxide production from CLA increased about 12 -fold at $10 \mathrm{hr}$ after heat treatment at $100^{\circ} \mathrm{C}$, whereas Arg/CLA complex did not exhibit significant hydroperoxide production [60]. The Arg/CLA complex showed synergistic anti-oxidant activity in a 2,2'azinobis(3-ethylbenzothiazoline)-6-sulfonic acid (ABTS) radical scavenging assay (Fig. 3). It was found that Arg/ CLA complex at $20 \mathrm{mM}$ scavenged $89 \%$ of ABTS radicals in $3 \mathrm{~h}$, whereas CLA alone quenched only $48 \%$ under the same conditions, suggesting that a hydrophilic Arg/CLA complex exhibited enhanced oxidative stability and antioxidant activity, which may expand the scope of CLA applications in various food industries. Recent research had been aimed to elucidate the physiological background of CLA-inducing reduction in adipose tissue mass $[61,62]$. However, some concerns had been aroused on the potential implication of the CLA in insulin resistance and fatty liver under certain conditions [63-65]. Because Arg infusion was known to have a preventive role in the insulin resistance by decreasing the total plasma homocysteine concentration [66] and antioxidant capacity $[66,67]$, the formation of Arg/CLA complex could alleviate the potential side effects, if any, resulted from the high dose of CLA. Thus, the presence of Arg in the form of complex with CLA may expand the scope of the application of CLA as a health-promoting agent.

\section{4. Amylase/CLA complex}

Most of the interest in amylase/lipid complexes focused on their technological importance in the starch food system, since they modified the texture and structural stability of starch based-product (e. g., reduction in stickiness, improved freeze-thaw stability, and retardation of retro- 


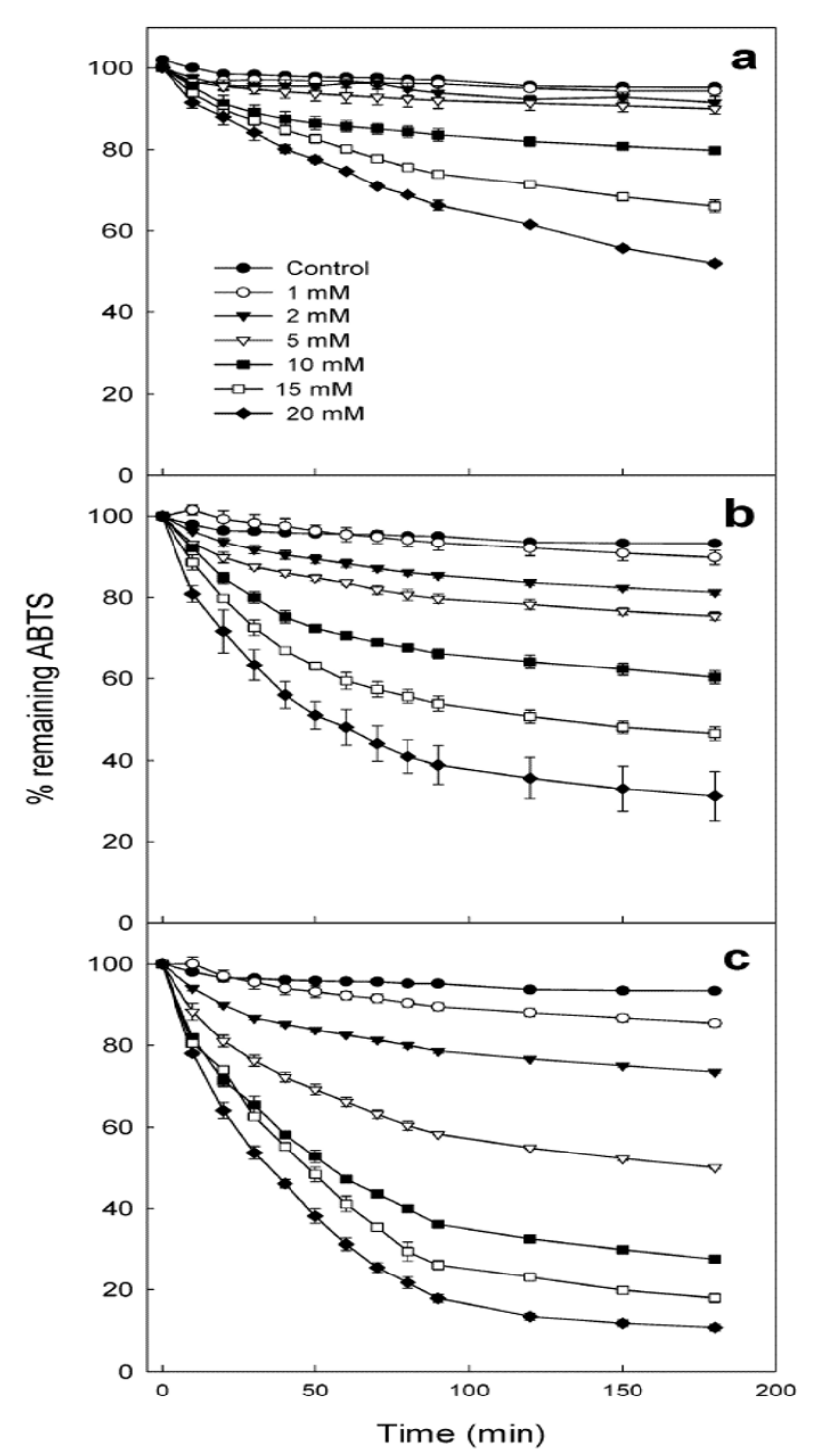

Figure 3

Kinetics of reaction of ABTS radicals with (a) CLA, (b) Arg, and (c) Arg-CLA. Each test compound at 0, I, 2, 5, I0, I5, and $20 \mathrm{mM}$ was reacted with $100 \mu \mathrm{M}$ ABTS radicals. Error bars represent standard deviations of each data point $(n=3)$ (J Agric Food Chem 2004, 52:439-444).

gradation) $[68,69]$. Other researchers studied amylase/ lipid complexes in view of their contribution to the bioavailability of starch, in terms of its enzymatic digestion [70]. It was shown that the V-form could be produced from mono- and di-glycerides, and saturated fatty acids, as well as un-saturated fatty acids $[70,71]$. The protection against oxidation afforded to CLA by its inclusion in an amylase complex demonstrated the potential of the complexes, especially those created in water/dimethyl sulfoxide (DMSO) solution, to efficiently protect CLA from oxidation [72]. It was shown that the peaks of the diffractograms obtained from complexes made in $\mathrm{KOH} / \mathrm{HCl}$ solution were narrower than those obtained from complexes created by water/DMSO solution, indicating that these complexes were composed of large crystals. Also, the complexes created in water/DMSO solution at $90^{\circ} \mathrm{C}$ revealed globural structures of heterogeneous nature with an average z-range of $71.6 \pm 59 \mathrm{~nm}$ and diameter of $152 \pm$ $39 \mathrm{~nm}$. Fig. 4 shows oxidation of CLA on each water/ $\mathrm{DMSO}$ and $\mathrm{KOH} / \mathrm{HCl}$ solution, indicating that the protective effect of complexes against CLA oxidation was higher for complexes created in water/DMSO solution than that for $\mathrm{KOH} / \mathrm{HCl}$ solution, suggesting that complexes created in water/DMSO solution exhibited better protective ability from oxidation. Hence, these results indicate that the amylase/lipid complex system could serve as a vehicle for delivery of PUFA to the intestine and potential use of amylase/lipid complexes could be supplementation of various stable foods with PUFA.

\section{5. PEGylation}

Poly(ethylene glycol) (PEG) was a nontoxic, water-soluble polymer widely used for stabilizing colloids in foods and paints and in formulating pharmaceuticals and cosmetics [73]. Generally, covalent attachment of activated PEG to proteins altered protein properties, such as increased solubility and stability in organic solvents, increased thermal stability, and reduced immunogenicity and antigenicity, in ways that extend their potential uses [74-76]. Also, PEGylation provided a higher stability owing to the formation of core-shell type nanoparticels (NPs) when compared to the non-modified drug [77]. In fact, PEGylated drugs such as core-shell type polymeric NPs increased stability in air, light, $\mathrm{pH}$, and temperature $[74,76]$. Support for these results, as shown in Fig. 5A, the concentration of intact all-trans retinoic acid (atRA) in the methanol solution rapidly decreased during incubation at room temperature under light exposure whereas the rate of PEGylated atRA (PRA) degradation was very slow [78]. Also, we previously reported that PEGylated CLA (PCLA) had increased bioavailability than CLA due to the biocompatible and hydrophilic properties of PEG, and peroxisome proliferator activated receptor gamma 2 -induced adipogenesis was reduced by PCLA [79]. In addition, we further demonstrated that a time-dependent effect on lipolysis and p-extracellular signal-related kinases (ERK) expression was observed for PCLA-treated, but not for CLA-treated cultures [80], suggesting that the induction by PCLA of mitogen-activated protein kinase kinase (MEK)/ERK mitogen-activated protein kinase (MAPK) activation was linked to secretion of adipo-cytokines, interleukin-6 (IL-6), and interleukin-8 (IL-8), in timedependent manners. Our findings provide support for a role for PCLA as a pro-drug in the regulation of metabolism in adipose tissue. Moreover, we showed that the level 

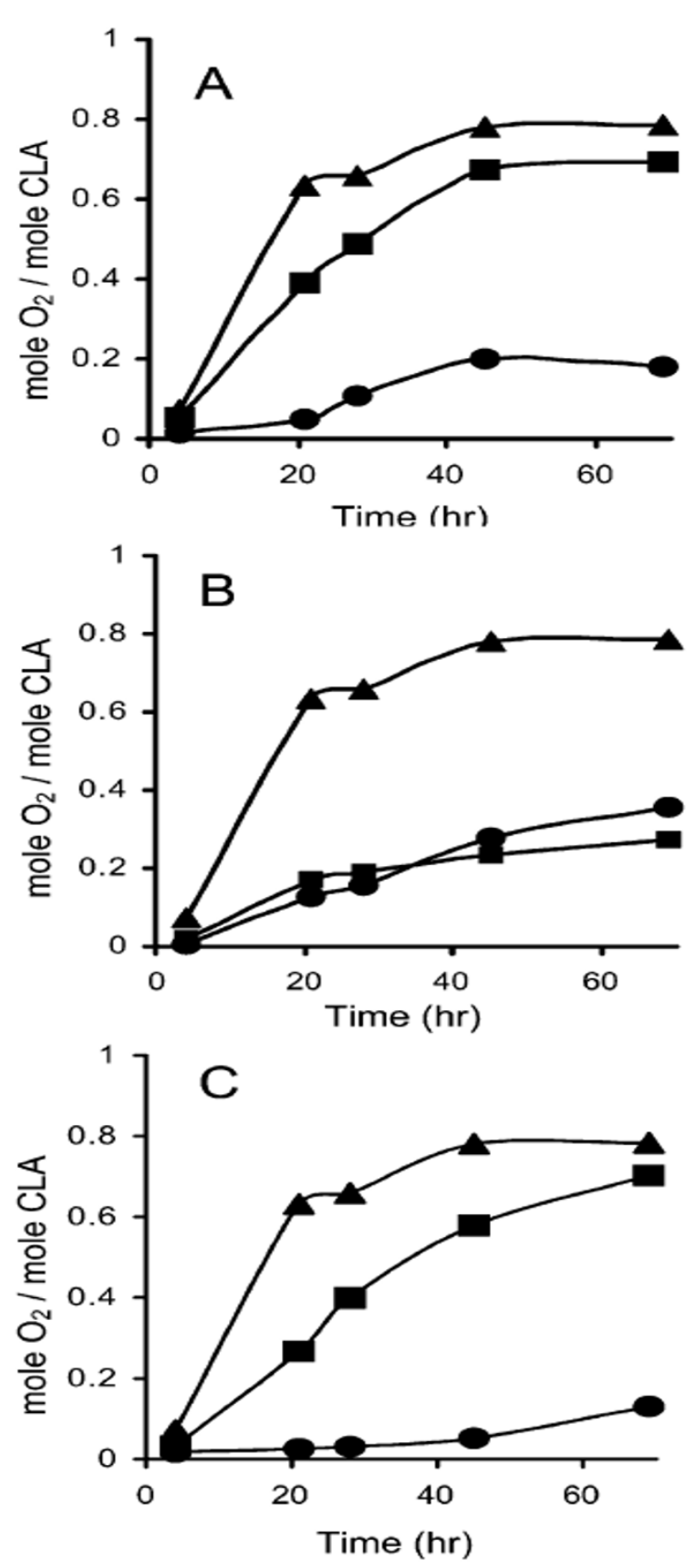

Figure 4

Headspace-oxygen analysis of complexes created at $90^{\circ} \mathrm{C}$ $(\mathrm{A}), 60^{\circ} \mathrm{C}(\mathrm{B})$, and $30^{\circ} \mathrm{C}(\mathrm{C})$ in water/DMSO solution $(\bullet)$ and by $\mathrm{KOH} / \mathrm{HCl}$ solution (-), with comparison to free $\mathrm{CLA}(\mathrm{s})$ (Biomacromolecules 2005, 6:121-130).

of headspace oxygen decreased by PCLA was lower than that decreased by CLA, indicating that the oxidation of CLA was significantly protected by PEGylation, as shown in Fig. 5B (unpublished data). Hence, observations with PEGylation regarding their biological and CLA-protected effects are encouraging and their use in a variety of biological activity, oxidative stability and post-ruminal bioavailability must not be ignored.

\section{Summary}

CLA have numerous potential health benefits, and the fats from milk and meats of ruminants are the richest natural dietary sources of CLA. Manipulating the diets of dairy and beef cattle and altering management practices on the farm could enhance the CLA contents of milk and dairy products and beef products. Also, the CLA contents of milk, dairy products, meat, and meat products vary widely, and the CLA intake by humans have the potential to increase to a level that have been shown to reduce the incidence of cancer in animal models through the consumption of CLA-enriched dairy and beef products. However, CLA are rapidly decomposed to form furan fatty acids when its are oxidized in air, and the effectiveness of dietary supplements of CLA may be related to the extent that their metabolism by rumen bacteria is avoided. To overcome with these phenomena, many investigations have examined the effect of manufacturing and protection on stability of CLA in ruminants and food products such as rumen-protected methods including $\mathrm{Ca}, \mathrm{Fa}, \mathrm{AP}$, and $\mathrm{LE}$, and oxidative stability methods such as GTC, CD, Arg, and amylase. All of these modifications, however, there are short-term study with very limited animal numbers; further research with these supplements will be needed to verify and extend results. Also, before CLA supplementation are recommended for human beings, controlled research studies using single isomers of CLA need to be completed to determine its efficacy and safety. Moreover, it is still questionable whether high levels of trans10, cis12 in milk are indeed desired-especially taking into consideration that trans 10 , cis 12 is not really a naturally occurring fatty acid although CLA, specifically trans10, cis12, might be detrimental to human health. However, suffice it to say that observations with CLA regarding their possible health effects are encouraging and their use in a variety of functional foods are a distinct possibility that should be interested.

\section{Abbreviations}

CLA: Conjugated linoleic acid; DHA: docosahexanenoic acid; ACA: arachidonic acid; LA: linoleic acid; PUFA: polyunsaturated fatty acid; FFA: free fatty acids; Ca-CLA: calcium salts-CLA; FP-CLA: formaldehyde-protected-CLA; MFD: milk fat depression; AP: amide protection; LE: lipid encapsulation; CLA-ME: CLA-methyl esters; TBARS: thiobarbituric acid reactive substances; EGC: (-)-epigallocatechin; C: (+)-catechin; EGCG: (-)-epigallocatechin-3gallate; EC: (-)-epicatechin; ECG: (-)-epicatechin gallate; GTC: green tea catechins; BHT: butylated hydroxytoluene; CDs: cyclodextrins; POV: peroxide values; Arg: Arginine; ABTS: 2,2'-azinobis(3-ethylbenzothiazoline)-6-sulfonic 

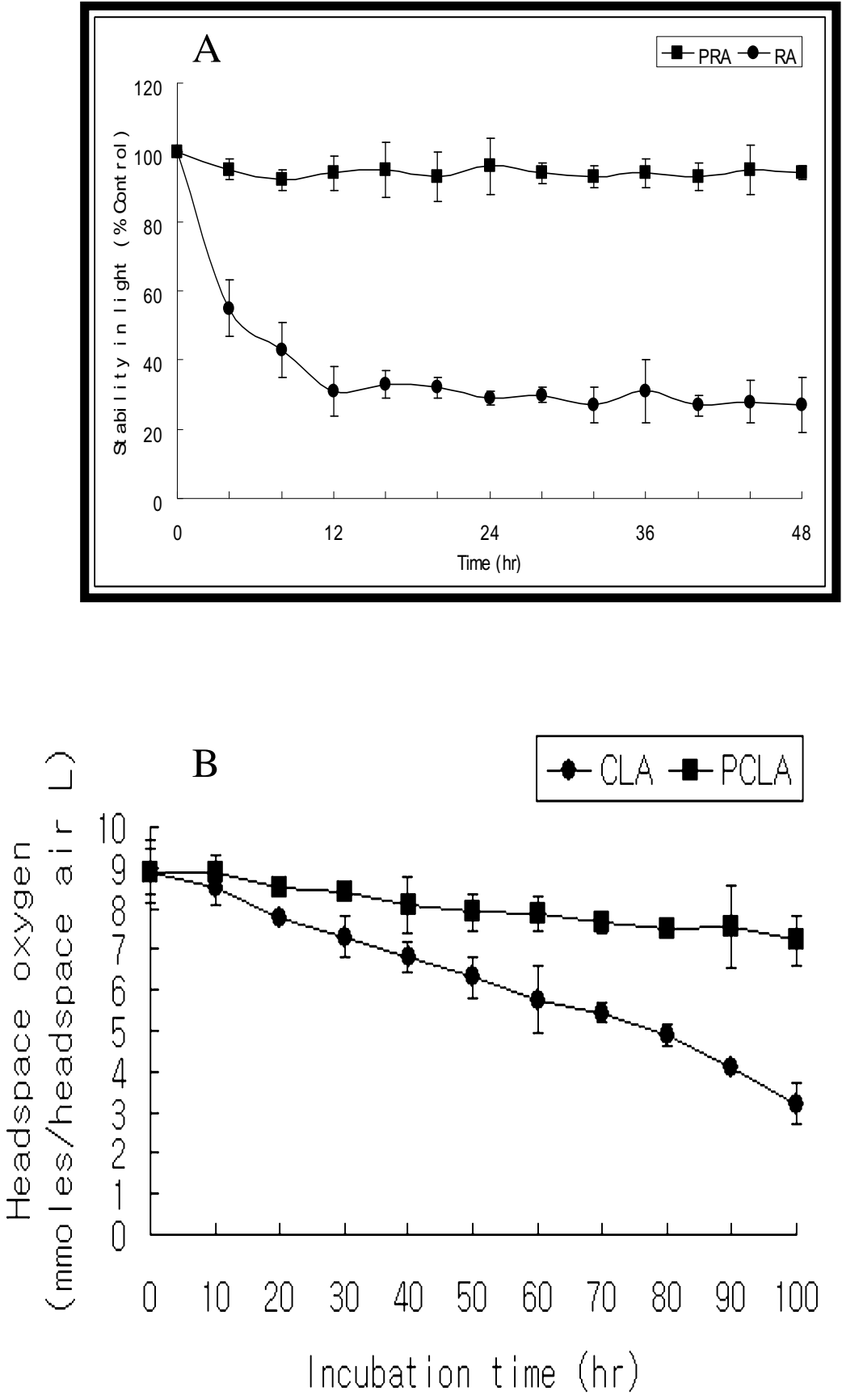

Figure 5

(A) Stability test of PRA. At specific time intervals, changes in the absorbance were determined through UV absorbance spectroscopy at $350 \mathrm{~nm}$. The concentration of intact RA in the methanol solution rapidly decreased as compared to that of PRA during incubation at room temperature under light exposure. Each experiment was performed in triplicate. Values are means \pm SD (J Nutr Biochem 2007, 18:322-33I). (B) Headspace-oxygen depletion by CLA and PCLA. Headspace oxygen in the sample bottles was analyzed by injecting a $100 \mu \mathrm{L}$ headspace air sample into a HP $5890 \mathrm{GC}$ (Avondale, PA), equipped with a stainless steel molecular sieve column (I3×, 80:100; Alltech, Deerfield, IL) and a thermal conductivity detector. High purity helium (99.99\%) was used as the carrier gas. The flow rate was $40 \mathrm{~mL} / \mathrm{min}$. The $\mathrm{GC}$ oven temperature was maintained at $40^{\circ} \mathrm{C}$. The injector port and detector temperatures were maintained at 120 and $150^{\circ} \mathrm{C}$, respectively. Each sample was analyzed in triplicate. Oxygen contents were quantified by an HP 3396A integrator (unpublished data). 
acid; DMSO: dimethyl sulfoxide; PEG: Poly(ethylene glycol); BSA: bovine serum albumin; $\beta$-lg: $\beta$-lactoglobulin; PCLA: PEGylated CLA; NPs: nanoparticles; RA: rumenic acid; VA: vaccenic acid.

\section{Authors' contributions}

MHS designed and wrote this manuscript. LHG, CCS, CYJ, and CCS conceived of the study, and participated in its design and co-ordination. All authors read and approved the final manuscript.

\section{Acknowledgements}

This work was supported by the Agricultural R\&D Promotion Center (ARPC) (I06I24-03-2-SB0I0).

\section{References}

I. Wahle KWJ, Sheys SD, Rotondo D: Conjugated linoleic acids: are they beneficial or detrimental to health? Prog Lipid Res 2004, 43:553-587.

2. IP C, Scimeca JA, Thompson HJ: Conjugated linoleic acid. A powerful anticarcinogen from animal fat sources. Cancer 1994, 74: $1050-1054$

3. Lee KN, Kritchevsky D, Pariza MW: Conjugated linoleic acid and atherosclerosis in rabbits. Atherosclerosis 1994, 108: 19-25.

4. Cook MR, Miller CC, Park Y, Pariza MW: Immune modulation by altered nutrient metabolism: nutritional control of immuneinduced growth depression. Poult Sci 1993, 72: | 30I-I 305.

5. Cantwell H, Devery R, Stanton C, Lawless F: The effect of a conjugated linoleic acid on superoxide dismutase, catalase and glutathione peroxidase in oxidatively-challenged liver cells. Biocehm Soc Trans 1998, 26(I):S62.

6. Belury MA, Kempa-Steczko A: Conjugated linoleic acid modulates hepatic lipid composition in mice. Lipids 1997, 32:199-204.

7. Pariza MW, Park Y, Cook ME: Mechanisms of action of conjugated linoleic acid: evidence and speculation. Proc Soc Exp Biol Med 2000, 223:8-13.

8. Pariza MW, Park Y, Cook ME: The biologically active isomers of conjugated linoleic acid. Prog Lipid Res 200I, 40:283-298.

9. Brown JM, Halvorsen YD, Lea-Currie YR, Geigerman C, Mclntosh M: Trans- I O, cis- I 2, but not cis-9, trans-II, conjugated linoleic acid attenuates lipogenesis in primary cultures of stromal vascular cells from human adipose tissue. I Nutr 200I, | 3 |:23|6-232|.

10. Mir PS, McAllister TA, Scott S, Aalhus J, Baron V, McCartney D, Charmley E, Goonewardene L, Basarab J, Okine E, Weselake RJ, Mir $\mathrm{Z}$ : Conjugated linoleic acid-enriched beef production. $\mathrm{Am} \mathrm{J}$ Clin Nutr 2004, 79: I 207S-I2IIS.

II. Corino C, Magni S, Pastorelli G, Rossi R, Mourot J: Effect of conjugated linoleic acid on meat quality, lipid metabolism, and sensory characteristics of dry-cured hams from heavy pigs. $J$ Anim Sci 2003, 81:2219-2229.

12. Cook MR, Miller CC, Park Y, Pariza MW: Immune modulation by altered nutrient metabolism: nutritional control of immuneinduced growth depression. Poult Sci 1993, 72:1301-I305.

13. Perfield JW, Lock AL, Pfeiffer AM, Bauman DE: Effects of amideprotected and lipid-encapsulated conjugated linoleic acid supplements on milk fat synthesis. J Dairy Sci 2004, 87:3010-3016.

14. Chen ZY, Kwan KY, Tong KK, Ratnayake WM, Li HQ, Leung SS: Breast milk fatty acid composition: a comparative study between Hong Kong and Chongqing Chinese. Lipids 1997, 32: $1061-1067$

15. de Veth MJ, Gulati SK, Luchini ND, Bauman DF: Comparison of calcium salts and formaldehyde-protected conjugated linoleic Acid in inducing milk fat depression. J Dairy Sci 2005, 88: $1685-1693$.

16. Whalley LJ, Fox HC, Wahle KW, Starr JM, Deary II: Cognitive aging, childhood intelligence, and the use of food supplements: possible involvement of $\mathbf{n}-\mathbf{3}$ fatty acids. Am J Clin Nutr 2004, 80: 1650-1657.
17. McGuire MA, McGuire MK, Parodi PW, Jensen RG: Advances in conjugated linoleic acid research. Volume I. AOCS Press, Champaign (IL); 1999:295-306.

18. Parodi PW: Advances in conjugated linoleic acid research. Volume 2. AOCS Press, Champaign (IL); 2003:I01-I 22.

19. Parodi PW: Cows' milk fat components as potential anticarcinogenic agents. J Nutr 1997, I 27:1055-1060.

20. Gulati SK, Cook LJ, Ashes JR, Scott TW: Effect of feeding protected cholesterol on ruminant milk fat secretion. Lipids I978, 13:8|4-819.

21. Kepler CR, Tove SB: Biohydrogenation of unsaturated fatty acids. 3. Purification and properties of a linoleate delta- I 2cis, delta-I I-trans-isomerase from Butyrivibrio fibrisolvens. J Biol Chem 1967, 242:5686-5692.

22. Christie WW, Dobson G, Gunstone FD: Some physical, chemical, and biological properties of natural and synthetic unsaturated CI 8 acids. J Am Oil Chem Soc 1973, 50:486A-490A.

23. Sehat N, Kramer JKG, Mossoba MM, Yurawecz MP, Roach JAG, Eulitz $\mathrm{K}$, Morehouse $\mathrm{KM}, \mathrm{Ku} \mathrm{Y}$ : Identification of conjugated linoleic acid isomers in cheese by gas chromatography, silver ion high performance liquid chromatography and mass spectral reconstructed ion profiles. Comparison of chromatographic elution sequences. Lipids 1998, 33:963-97I.

24. Scimeca JA: Toxicological evaluation of dietary conjugated linoleic acid in male Fischer 344 rats. Food Chem Toxicol I 998, 36:391-395.

25. Gaullier JM, Breven G, Blankson H, Gudmondsen O: Clinical trial results support a preference for using CLA preparations enriched with two isomers rather than four isomers in human studies. Lipids 2002, 37:1019-1025.

26. Kamphuis MMJW, Lejeune MPGM, Saris WHM, Westerterp-Plantenga MS: Effect of conjugated linoleic acid supplementation after weight loss on appetite and food intake in overweight subjects. Eur J Clin Nutr 2003, 57: I 268-I 274.

27. Zambell KL, Keim NL, Van Loan MD: Conjugated linoleic acid supplementation in humans: effects on body composition and energy expenditure. Lipids 2000, 35:777-782.

28. Thom E, Wadstein J, Gudmundsen O: Conjugated linoleic acid reduces body fat in healthy exercising humans. J Int Med Res 2001, 29:392-396.

29. Blankson H, Stakkestad JA, Fagertun H, Thom E, Wadstein J, Gudmundsen $\mathrm{O}$ : Conjugated linoleic acid reduces body fat mass in overweight and obese humans. J Nutr 2000, I 30:2943-2948.

30. Riserus U, Berglund L, Vessby B: Conjugated linoleic acid (CLA) reduced abdominal adipose tissue in obese middle-aged men with signs of the metabolic syndrome: a randomised controlled trial. Int J Obes Relat Metab Disord 2001, 25: I I29-II 35.

31. Kamphuis MM, Lejeune MP, Saris WH, Westerterp-Plantenga MS: The effect of conjugated linoleic acid supplementation after weight loss on body weight regain, body composition, and resting metabolic rate in overweight subjects. Int J Obes Relat Metab Disord 2003, 27:840-847.

32. Bhattacharya A, Banu J, Rahman M, Causey J, Fernandes G: Biological effects of conjugated linoleic acids in health and disease. J Nutr Biochem 2006, I 2:789-8I0.

33. Gillis MH, Duckett SK, Sackmann JR: Effects of supplemental rumen-protected conjugated linoleic acid or corn oil on fatty acid composition of adipose tissues in beef cattle. J Anim Sci 2004, 82:|4|9-| 427.

34. Bauman DE, Griinari JM: Nutritional regulation of milk fat synthesis. Annu Rev Nutr 2003, 23:203-227.

35. Wu Z, Papas A: Rumen-stable delivery systems. Adv Drug Deliv Rev 1997, 28:323-334.

36. Giesy JG, McGuire MA, Shafii B, Hanson TW: Effect of dose of calcium salts of conjugated linoleic acid (CLA) on percentage and fatty acid content of milk fat in midlactation holstein cows. J Dairy Sci 2002, 85:2023-2029.

37. Bernal-Santos G, Perfield JW, Overton TR, Bauman DE: Production responses of dairy cows to dietary supplementation with conjugated linoleic acid (CLA) during the transition period and early lactation. J Dairy Sci 2003, 86:32 I8-3228.

38. Chouinard PY, Corneau DM, Barbano LE, Bauman DE: Conjugated linoleic acids alter milk fatty acid composition and inhibit milk fat secretion in dairy cows. J Nutr 1999, I 29: I579-I 584.

39. de Veth MJ, Griinari JM, Pfeiffer AM, Bauman DE: Effect of CLA on milk fat synthesis in dairy cows: comparison of inhibition by 
methyl esters and free fatty acids, and relationships among studies. Lipids 2004, 39:365-372

40. Yang L, Leung LK, Huang Y, Chen ZY: Oxidative stability of conjugated linoleic acid isomers. I Agric Food Chem 2000, 48:3072-3076

4I. Gulati SK, Wijesundera C, Byers E, Scott TW: Rumen protected conjugated linoleic acid (CLA) methyl esters decrease milk fat and increase CLA concentration in goat milk. Asia Pac J Clin Nutr 2003, I 2:S44

42. Baumgard LH, Corl BA, Dwyer DA, Sæbø A, Bauman DE: Identification of the conjugated linoleic acid isomer that inhibits milk fat synthesis. Am J Physiol Regul Integr Comp Physiol 2000, 278:RI79-RI84

43. Viswanadha S, Giesy JG, Hanson TW, McGuire MA: Dose response of milk fat to intravenous administration of the trans-10, cis12 isomer of conjugated linoleic acid. J Dairy Sci 2003, 86:3229-3236.

44. Ip C, Chin SH, Scimeca JA, Pariza MW: Mammary cancer prevention by conjugated dienoic derivative of linoleic acid. Cancer Res 1991, 51:61|8-6124.

45. Joo ST, Lee J], Ha YL, Park GB: Effects of dietary conjugated linoleic acid on fatty acid composition, lipid oxidation, color, and water-holding capacity of pork loin. J Anim Sci 2002, 80: I08-II 2

46. Chin SF, Storkson JM, Liu W, Albright KJ, Pariza MW: Conjugated linoleic acid (9,1I- and 10,12-octadecadienoic acid) is produced in conventional but not germ-free rats fed linoleic acid. J Nutr 1994, I 24:694-70I.

47. Zhang A, Zhu QY, Luk YS, Ho KY, Fung KP, Chen ZY: Inhibitory effects of jasmine green tea epicatechin isomers on free radical-induced lysis of red blood cells. 1994.

48. Berg JJ Van den, Cook NE, Tribble DL: Reinvestigation of the antioxidant properties of conjugated linoleic acid. Lipids 1995, 30:599-605.

49. Imai K, Litt D, Suga K, Nakachi K: Cancer-preventive effects of drinking green tea among a Japanese population. Prev Med 1997, 26:769-775.

50. Yudkin JS, Kumari M, Humphries SE, Mohamed-Ali V: Inflammation, obesity, stress and coronary heart disease: is interleukin-6 the link? Atherosclerosis 2000, 148:209-2। 4 .

5I. Nagao A, Seki M, Kobayashi H: Inhibition of xanthine oxidase by flavonoids. Biosci Biotechnol Biochem 1999, 63:1787-1790.

52. Yuki E, Iskikawa Y: Tocopherol contents of nine vegetable frying oils, and their changes under simulated deep-fat frying conditions. J Am Oil Chem Soc 1976, 53:673-676.

53. Chichlowski MW, Schroeder JW, Park CS, Keller WL, Schimek DE: Altering the fatty acids in milk fat by including canola seed in dairy cattle diets. J Dairy Sci 2005, 88:3084-3094.

54. Schwick HG, Haupt $H$ : Chemistry and function of human plasma proteins. Angew Chem Int Ed Engl 1980, 19:87-99.

55. Divakar S: Determination of distances of sugar protons from Mn2+ in concanavalin A. Indian J Biochem Biophys 1989 26(3): $190-195$.

56. Hubbard WD, Sheppard AJ, Newkirk DR, Prosser AR, Osgood T: Comparison of various methods for the extraction of total lipids, fatty acids, cholesterol, and other sterols from food products. J Am Oil Chem Soc 1977, 54:8I-83.

57. Kim SJ, Park GB, Kang CB, Park SD, Jung MY, Kim JO, Ha YL: Improvement of oxidative stability of conjugated linoleic acid (CLA) by microencapsulation in cyclodextrins. J Agric Food Chem 2000, 48:3922-3929.

58. Moncada S, Palmer RMJ, Higgs EA: Nitric oxide: physiology, pathophysiology, and pharmacology. Pharmacol Rev 1991, 43: $109-142$

59. Gonsiorek W, Lunn C, Fan X, Narula S, Lundell D, Hipkin RW: Endocannabinoid 2-arachidonyl glycerol is a full agonist through human type 2 cannabinoid receptor: antagonism by anandamide. Mol Pharmacol 2000, 57: 1045-1050.

60. Kim YJ, Lee KW, Lee HJ: Total antioxidant capacity of arginineconjugated linoleic acid (CLA) complex. J Agric Food Chem 2004, 52:439-444.

61. Loor JJ, Herbein JH: Reduced fatty acid synthesis and desaturation due to exogenous trans I 0, cis I 2-CLA in cows fed oleic or linoleic oil. J Dairy Sci 2003, 86: $1354-1369$.

62. Park Y, Albright JK, Liu W, Storkson JM, Cook ME, Pariza MW: Effect of conjugated linoleic acid on body composition in mice. Lipids 1997, 32:853-858.
63. Tsuboyama-Kasaoka N, Takahashi M, Tanemura K, Kim HJ, Tange T, Okuyama H, Kasai M, Ikemoto S, Ezaki O: Conjugated linoleic acid supplementation reduces adipose tissue by apoptosis and develops lipodystrophy in mice. Diabetes 2000, 49:1534-1542.

64. Clement L, Poirier H, Niot I, Bocher V, Guerre-Millo M, Krief S, Staels $B$, Besnard P: Dietary trans-10,cis- 12 conjugated linoleic acid induces hyperinsulinemia and fatty liver in the mouse. J Lipid Res 2002, 43:1 400-I 409.

65. Cassone Faldetta M, Laurenti O, Desideri G, Bravi MC, De Luca O Marinucci MC, De Mattia G, Ferri C: L-arginine infusion decreases plasma total homocysteine concentrations through increased nitric oxide production and decreased oxidative status in Type II diabetic patients. Diabetologia 2002, 45: II20-III27.

66. Yu L, Adams D, Gabel M: Conjugated linoleic acid isomers differ in their free radical scavenging properties. J Agric Food Chem 2002, 50:4|35-4|40.

67. Yu L: Free radical scavenging properties of conjugated linoleic acids. J Agric Food Chem 200I, 49:3452-3456.

68. Berry RK, Dekker RF: Fractionation of the cellulolytic enzymes produced by a species of Monilia; purification and properties of an extracellular beta-D-glucosidase. Carbohydr Res 1986, 157:1-12.

69. Mori N, Bai Y, Ueno H, Manning JM: Sequence-dependent reactivity of model peptides with glyceraldehyde. Carbohydr Res 1989, 189:49-63.

70. Shin A, Li H, Shu XO, Yang G, Gao YT, Zheng W: Dietary intake of calcium, fiber and other micronutrients in relation to colorectal cancer risk: Results from the Shanghai Women's Health Study. Int J Cancer 2006, I I 9:2938-2942

7I. Related Articles, Yan HJ, Lee EJ, Nam KC, Min BR, Ahn DU: Dietary functional ingredients: performance of animals and quality and storage stability of irradiated raw turkey breast. Poult Sci 2006, 85: 1829-1837.

72. Lalush I, Bar H, Zakaria I, Eichler S, Shimoni E: Utilization of amylose-lipid complexes as molecular nanocapsules for conjugated linoleic Acid. Biomacromolecules 2005, 6:121-130.

73. DeSantis G, Jone JB: Chemical modification of enzymes for enhanced functionality. Curr Opin Biotechnol 1999, 10:324-330.

74. Delgado C, Francis GE, Fisher D: The uses and properties of PEG-linked proteins. Crit Rev Ther Drug Carrier Syst 1992, 9:249-304.

75. Zalipsky S, Mullah N, Engbers C, Hutchins MU, Kiwan R: Thiolytically cleavable dithiobenzyl urethane-linked polymer-protein conjugates as macromolecular prodrugs: reversible PEGylation of proteins. Bioconjug Chem 2007, 18:1869-1878.

76. Losso JN, Nakai S: Stabilization of oil-in-water emulsions by beta-lactoglobulin-polyethylene glycol conjugates. J Agric Food Chem 2002, 50:1207-1212.

77. Kim K, Luu YK, Chang C, Fang D, Hsiao BS, Chu B, Hadjiargyrou M: Incorporation and controlled release of a hydrophilic antibiotic using poly(lactide-co-glycolide)-based electrospun nanofibrous scaffolds. I Control Release 2004, 98:47-56.

78. Moon HS, Guo DD, Song HH, Kim IY, Jiang HJ, Kim YK, Chung CS, Choi YJ, Lee HJ, Cho CS: Regulation of adipocyte differentiation by PEGylated all-trans retinoic acid: reduced cytotoxicity and attenuated lipid accumulation. J Nutr Biochem 2007, I8:322-33|.

79. Moon HS, Lee HG, Seo JH, Chung CS, Kim TG, Kim IY, Lim KW, Seo SJ, Choi YJ, Cho CS: Down-regulation of PPARgamma2induced adipogenesis by PEGylated conjugated linoleic acid as the pro-drug: Attenuation of lipid accumulation and reduction of apoptosis. Arch Biochem Biophys 2006, 456: 19-29.

80. Moon HS, Lee HG, Seo JH, Guo DD, Kim IY, Chung CS, Kim TG, Choi YJ, Cho CS: Lipolysis is stimulated by PEGylated conjugated linoleic acid through the cyclic adenosine monophosphate-independent signaling pathway in 3T3-LI cells: activation of MEK/ERK MAPK signaling pathway and hypersecretion of adipo-cytokines. J Cell Physiol 2008, 21 4:283-294. 